\title{
Western Mediterranean sea-level rise: changing exchange flow through the Strait of Gibraltar
}

\author{
Tetjana Ross and Chris Garrett \\ Department of Physics and Astronomy, University of Victoria, B.C., Canada.
}

\section{Pierre-Yves Le Traon}

Oceanography Department, CLS Space Oceanography Division, France.

\begin{abstract}
Sea-level data from tide gauges and satellite altimetry show a decrease of nearly $40 \%$ in the sea-level drop between the Atlantic and the Mediterranean from 1994 to 1997 , coming mainly from a rapid rise of western Mediterranean sea-level by more than $10 \mathrm{~mm} /$ year. A decrease in the sea-level difference across the Strait, coincident with this Mediterranean rise, indicates that the surface inflow is reduced by an amount dynamically consistent with the change along the strait. These secular changes are accompanied by a seasonal cycle in the sea-level drop between the Atlantic and the Mediterranean, which indicates a seasonal flipping of hydraulic exchange states in the Strait of Gibraltar. Thus, we suggest the sea-level rise in the Mediterranean is a consequence of a changing exchange flow through the Strait of Gibraltar, driven indirectly by changing conditions in the Mediterranean.
\end{abstract}

\section{Introduction}

Changes in sea-level caused by climate change are a matter of global concern and would have a major impact in the Mediterranean region. In the Mediterranean Sea the monthly mean sea-level changes seasonally by more than can be attributed to thermal expansion and contraction [Larnicol et al., 1995], apparently as a consequence of a seasonal cycle in the sea-level drop between the Atlantic and Mediterranean. Past studies [Bormans and Garrett, 1989; Garrett et $a l ., 1990 \mathrm{a}, \mathrm{b}$ ] have argued that the seasonal cycle in the Atlantic to Mediterranean sea-level drop is due to a seasonal flipping back and forth between two different exchange states in the Strait of Gibraltar. The phase of this flipping is such that it adds to the steric changes in Mediterranean sea-level.

The exchange through the Strait of Gibraltar is driven by an excess of evaporation over precipitation and some cooling in the Mediterranean, leading to an outflow of dense salty Mediterranean water underneath fresher incoming Atlantic water. Hydraulic models of this exchange [Bryden and Stommel, 1984; Farmer and Armi, 1986; Bryden and Kinder, 1991] predict two possible states: maximal, which is hydraulically controlled at both Camarinal Sill and Tarifa Narrows and has a fast, thin, upper layer at the eastern end of the Strait; and submaximal, which is controlled only at the sill and has a slower, thicker upper layer.

Copyright 2000 by the American Geophysical Union.

Paper number 2000GL011653.

0094-8276/00/2000GL011653\$05.00
In order to provide acceleration and balance friction there is a sea-level drop along the strait up to the point where the current separates from the north coast. For maximal exchange the separation point is between Tarifa Narrows and Algeciras [Farmer and Armi, 1988], whereas for submaximal exchange it is probably near Algeciras. Simple dynamical models suggest the sea-level drop along the north shore is about $200 \mathrm{~mm}$ for maximal exchange and less than about 90 mm for submaximal exchange [Bormans and Garrett, 1989]. A seasonal switch between these two states, giving an average drop close to the $150 \mathrm{~mm}$ established by leveling [Levallois and Maillard, 1970], could account for the observed seasonality in the along-strait sea-level drop, though part of the seasonality may be associated with a changing density difference between the two layers [Bormans et al., 1986].

\section{Observations}

Monthly mean sea-level data are shown in Figure 1 for locations shown in Figure 2. The data have been adjusted for atmospheric pressure (e.g. [Le Traon and Gauzelin, 1997]) so that changes in the adjusted sea-level accurately reflect changes in pressure differences between stations. The raw sea-level data for Cadiz contained a downward drift of 14 $\mathrm{mm} /$ year from 1988 until the break in the record in 1993, but this drift was not seen at the nearby stations of Lagos and Setroia (Figure 2) and appears to have been spurious. We corrected this section of data by adding a trend equal to that at Setroia. After August 1993 the three stations were in agreement. Within the Mediterranean, the sea-levels at Malaga, Almeria and Alicante showed no major long term relative drifts.

As found in previous studies [Bormans et al., 1986; Garrett et al., 1990a; Larnicol et al., 1995], there is a seasonal signal at all stations and in the adjusted sea-level difference between Cadiz and Malaga (Figure 3). The seasonal cycle in the difference across the Strait of Gibraltar, from Ceuta to Algeciras, is less obvious.

What is new in these recent data is a strong trend from 1994 through 1997 in both differences. The sea-level difference between Cadiz and Malaga decreased by $14 \mathrm{~mm} /$ year, that from Ceuta to Algeciras by $12 \mathrm{~mm} /$ year. The decreasing sea-level drop between Cadiz and Malaga clearly comes from a rapid rise at Malaga which is also seen at Algeciras, Almeria and Alicante (Figures 1 and 2). The rise at Cadiz is more gradual. The four-year decrease of $56 \mathrm{~mm}$ in the drop from Cadiz to Malaga is nearly $40 \%$ of the long term mean of $150 \mathrm{~mm}$ established from leveling [Levallois and Maillard, $1970]$ and so is a major change. 


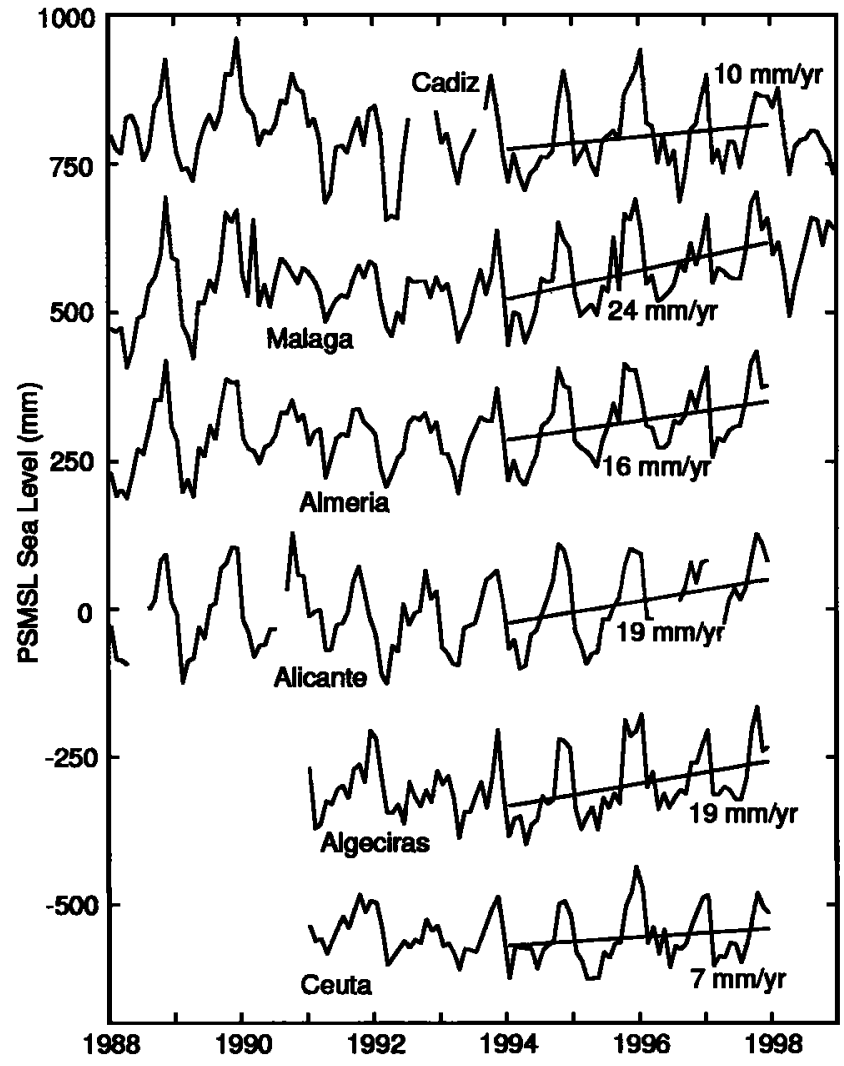

Figure 1. Monthly mean sea-level data for Cadiz, Malaga, Almeria, Alicante, Algeciras and Ceuta (in descending order). The records have been demeaned and offset for clarity. All the data have been barometrically corrected. The 1994-1997 slopes were calculated by fitting a combination of straight line and annual sinusoid to remove any effect on the mean from the annual cycle. The monthly means are plotted on the $\mathrm{x}$-axis in the middle of their respective month (e.g. May 1994 is $1994+4.5 / 12$ )

Similar results also appear in barometrically corrected sea-level data obtained from the Topex/Poseidon (T/P) satellite altimeter (Figure 4). As found earlier [Larnicol et al., 1995], there are seasonal variations with a range of about $200 \mathrm{~mm}$ in the Mediterranean, about twice the range in the north Atlantic, and hence there are associated seasonal variations in the difference. As with the tide gauge data, the altimeter data show a rapid rise in western Mediterranean sea-level from 1994 through 1997, though at a rate of 11 $\mathrm{mm} /$ year. The $\mathrm{T} / \mathrm{P}$ rate is lower, perhaps because it is an average over the entire western Mediterranean, thus combining different north and south shore rises and changes in interior circulation that may not be directly related to the Strait. The $\mathrm{T} / \mathrm{P}$ sea-level rise in the eastern north Atlantic (averaged over $7-12^{\circ} \mathrm{W} / 31-36^{\circ} \mathrm{N}$ ) for the same period was 8 $\mathrm{mm} /$ year, close to the value at Cadiz $(10 \mathrm{~mm} /$ year $) . \mathrm{T} / \mathrm{P}$ data also show that the along-strait difference decreased from 1994 through 1997 , though only at $4 \mathrm{~mm} /$ year. Interestingly, the $\mathrm{T} / \mathrm{P}$ data indicate that the rise in the western Mediterranean and the decrease in the difference from the Atlantic may have reversed in 1998 and 1999. The tide gauge data, however, show the trend in the drops continuing in 1998 (Figure 3).

\section{Discussion}

As mentioned above, the north shore along-strait sealevel drop for submaximal exchange $\left(\Delta \zeta_{s u b}=90 \mathrm{~mm}\right)$ is about half as big as the drop for maximal exchange $\left(\Delta \zeta_{\max }=\right.$ $200 \mathrm{~mm}$ ) [Bormans and Garrett, 1989]. Thus, the decreasing along-strait sea-level drops seem to indicate submaximal flow for an increasing fraction $(F)$ of the year:

$$
\begin{gathered}
\Delta \zeta=F \Delta \zeta_{\Delta u b}+(1-F) \Delta \zeta_{\max } \\
\frac{d}{d t}\left(\Delta \zeta_{\text {along }}\right)=-(110 \mathrm{~mm}) \frac{d F}{d t}
\end{gathered}
$$

Because of geostrophy, the sea-level on the south side of the strait is higher than on the north side. The difference is not firmly established but is about $200 \mathrm{~mm}$ and $100 \mathrm{~mm}$ for maximal and submaximal exchange respectively [Bormans and Garrett, 1989]. Thus, similar to (1),

$$
\frac{d}{d t}\left(\Delta \zeta_{a c r o s s}\right)=-(100 \mathrm{~mm}) \frac{d F}{d t}
$$

and, therefore, the simultaneous decrease in the across-strait sea-level drop also suggests a more frequent occurrence of the decreased inflow velocities which should accompany submaximal exchange. It seems the exchange was becoming more submaximal from 1994 through 1997.

Since the across-strait sea-level drops are comparable with the drops along the north shore, there should be little difference between Cadiz and the south shore inside the Mediterranean for either maximal or submaximal exchange, as seen in the similar rises at Ceuta and Cadiz (Figure 1). Nevertheless, a sea-level drop along the south shore is maintained, assuming that the inflow to the Strait is fed by a current along the south coast of Spain that lowers the sealevel at Cadiz by geostrophy.

The similar predicted drops across and along the strait for both maximal and submaximal exchange also suggest that, if an increasing fraction of the year being spent submaximal

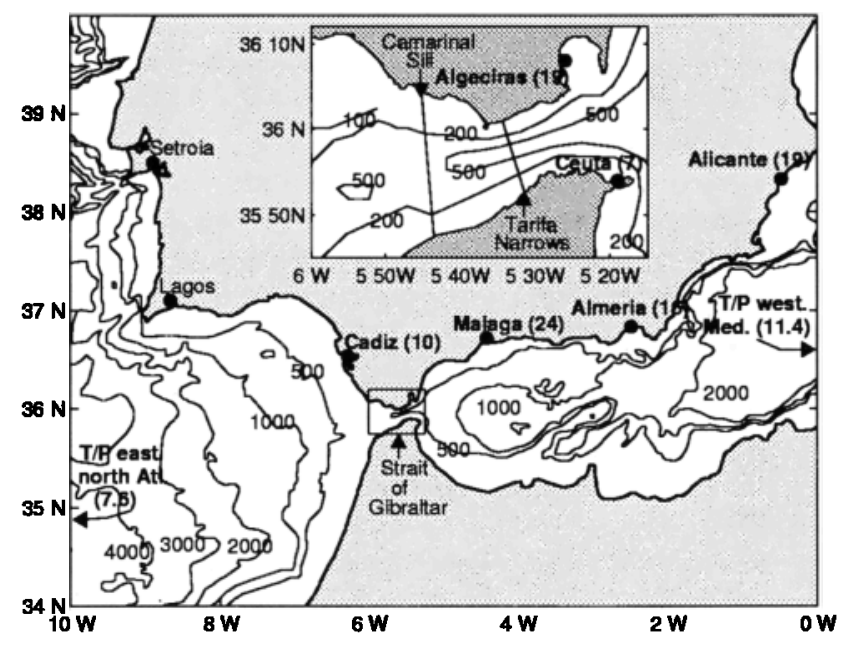

Figure 2. Map showing the locations of all sea-level stations mentioned in the text. The inset shows the bathymetry of the Strait of Gibraltar. All depths are in metres. The numbers beside the names are the 1994-1997 sea-level rise (in mm/year) at that station. $\mathrm{T} / \mathrm{P}$ west. Med. is an average of Topex/Poseidon data over the entire western Mediterranean. $T / P$ east. north Atl. is an average over the range $7-12^{\circ} \mathrm{W} / 31-36^{\circ} \mathrm{N}$. 


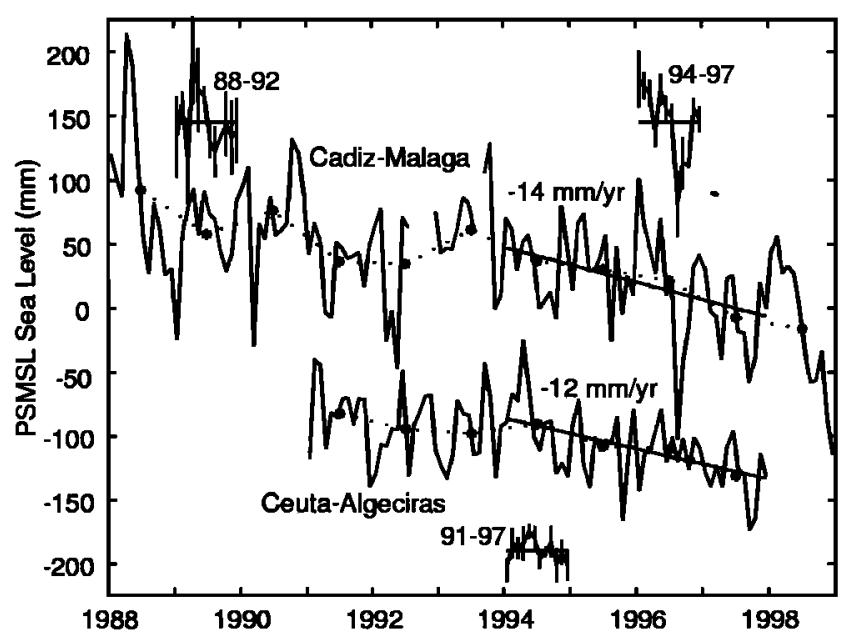

Figure 3. The along-strait sea-level drop between Cadiz and Malaga (top) and the across-strait sea-level drop between Ceuta and Algeciras (bottom). The drops have been demeaned and offset for clarity. All the data have been barometrically corrected. The 1994-1997 slopes were calculated by fitting a combination of straight line and annual sinusoid. The seasonal cycles (offset, with error bars) were calculated by averaging the departures from the annual mean $(\cdot * \cdot \cdot)$ and error bars are the standard error $\left(\sigma / n^{1 / 2}\right.$, $n$ being the number of years).

is causing the decrease in the drops, the ratio of the rate across to that along the strait should be about 0.9 , from the ratio of equations (2) and (1). This prediction is in good agreement with the value $12 / 14=0.9$ found here, although $95 \%$ confidence limits give a wide range (0.3-1.5) for the observed ratio.

The Malaga and Almeria records (Figure 1) suggest that the exchange may have switched from purely maximal to a combination of maximal and submaximal in 1993. Dur-
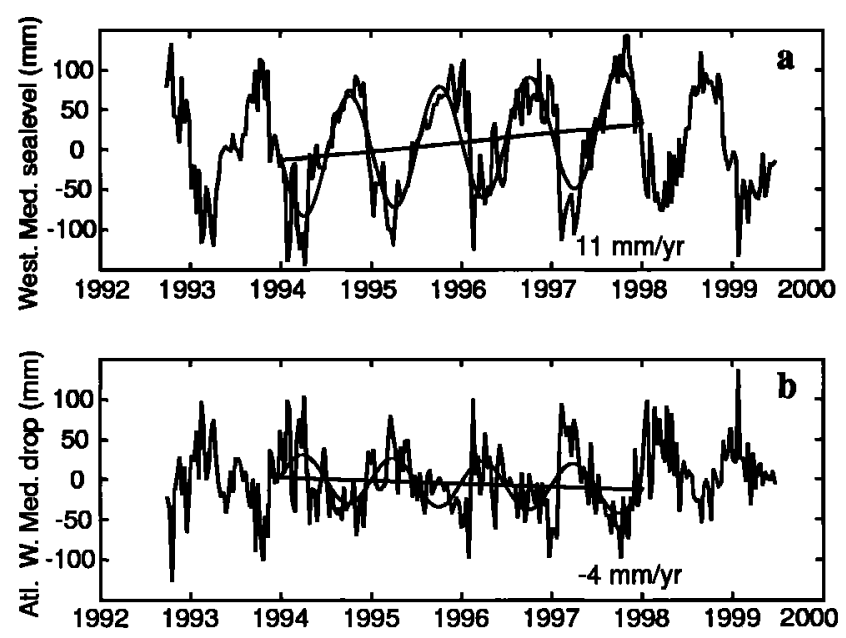

Figure 4. Topex/Poseidon satellite altimeter sea-level data; western Mediterranean mean sea-level (a) and north eastern Atlantic - western Mediterranean sea-level drop (b). There is an estimation of the mean sea-level, using tracks shown in previous papers [Hernandez et al., 1995; Larnicol et al., 1995; Le Traon and Gauzelin, 1997] for each 9.9 day cycle. All the Topex/Poseidon data are barometrically corrected. Also shown are fits of a superposition of an annual sinusoid and a straight line. ing 1990-1992 the range of their seasonal cycles was quite small (about $100 \mathrm{~mm}$ ), approximately the range predicted for thermal expansion and contraction [Larnicol et al., 1995]. We can therefore postulate that the exchange was purely maximal at that time. Starting in 1993, the seasonal ranges at Malaga and Almeria increased almost twofold (to about $200 \mathrm{~mm}$ ) - now too large to be explained by expansion and contraction alone. This sudden change can be explained if, by 1993 , the exchange was spending part of the year submaximal; a change also suggested by the fact that the seasonal cycles in the along-strait differences were more pronounced in 1994-1997 (Figure 3). These changes in the exchange flow may have been triggered by changes to deep water formation in the eastern Mediterranean prior to October 1991 [Malanotte-Rizzoli et al., 1999; Lascaratos et al., 1999]. The threefold increase in deep water formation [Roether et al., 1996] could have caused the interface between the Atlantic inflow and the dense Mediterranean water to rise (by wave propagation, not by immediate advection of the new dense water to the Strait of Gibraltar), forcing the exchange to become solely maximal and thus lowering the sea-level in the western Mediterranean. Then, during 1994-1997, the exchange recovered to its usual flipping between the two states as some dense water drained away, lowering the interface by about $10 \mathrm{~m} /$ year for an outflow rate of about 1 Sverdrup [Bryden and Kinder, 1991]. In 1998-1999, the trend may have continued (as suggested by tide gauge data) or may have reversed (as suggested by Topex/Poseidon data) and moved back to more maximal flow.

\section{Concluding remarks}

The 1994 through 1997 sea-level rise in the western Mediterranean was likely a result of changing exchange conditions in the Strait of Gibraltar triggered by changes in the Mediterranean. During that period the exchange may have moved from maximal exchange into a shared maximalsubmaximal regime.

Some studies have treated sea-level changes in the Mediterranean as if it were an isolated basin (e.g. [Tsimplis and Baker, 2000]). We stress, however, that sea-level changes in the Mediterranean cannot be considered independently of changes in the Atlantic and in the hydraulic state of the Strait of Gibraltar. The latter is a valuable choke point which affects changes in the Mediterranean and may also be used to detect them. It needs more comprehensive monitoring.

Acknowledgments. We are grateful to the Permanent Service for Mean Sea Level for all pre-1998 monthly tide gauge data, Maria Jesus García at the Instituto Español de Oceanografía for the 1998 tide gauge data, and the National Climatic Data Center (NCDC) for most of the sea-level pressure data. Some sea-level pressure data came from the National Center of Atmospheric Research (NCAR). We also thank Gary Mitchum and another reviewer for helpful comments.

\section{References}

Bormans, M., C. Garrett and K. Thompson, Seasonal variability of the surface inflow through the Strait of Gibraltar, Oceanologica Acta, 9, 403-414, 1986.

Bormans, M. and C. Garrett, The effects of nonrectangular cross section, friction, and barotropic fluctuations on the exchange through the Strait of Gibraltar, J. Phys. Oceanogr., 19, 1543$1557,1989$. 
Bryden, H. L. and T. H. Kinder, Recent progress in strait dynamics, Rev. Geophys., 29, 617-631, 1991.

Bryden, H. L. and H. M. Stommel, Limiting processes that determine basic features of the circulation in the Mediterranean Sea, Oceanologica Acta, 7, 289-296, 1984.

Farmer, D. M. and L. Armi, Maximal two-layer exchange over a sill and through the combination of a sill and contraction with barotropic flow, J. Fluid Mech., 64, 53-76, 1986.

Farmer, D. M. and L. Armi, The flow of Atlantic Water through the Strait of Gibraltar, Prog. Oceanog., 21, 1-105, 1988.

Garrett, C., K. Thompson and W. Blanchard, Sea-level flips, Nature, 348, 292, 1990a.

Garrett, C., M. Bormans and K. Thompson, Is the exchange through the Strait of Gibraltar maximal or submaximal?, in The Physical Oceanography of Sea Straits, edited by L. J. Pratt, pp. 271-294, Kluwer Academic Publishers, 1990b.

Hernandez, F., P.-Y. Le Traon and R. Morrow, Mapping mesoscale variability of the Azores Current using TOPEX/POSEIDON and ERS 1 altimetry, together with hydrographic and Lagrangian measurements, J. Geophys. Res., 100, 24995-25006, 1995.

Larnicol, G., P.-Y. Le Traon, N. Ayoub and P. DeMey, Mean sea level and surface circulation variability of the Mediterranean Sea from 2 years of TOPEX/POSEIDON altimetry, J. Geophys. Res., 100, 25163-25177, 1995.

Lascaratos, A., W. Roether, K. Nittis and B. Klein, Recent changes in deep water formation and spreading in the eastern Mediterranean Sea: a review, Prog. Oceanog., 44, 5-36, 1999.
Le Traon, P.-Y. and P. Gauzelin, Response of the Mediterranean mean sea level to atmospheric pressure forcing, J. Geophys. Res., 102, 973-984, 1997.

Levallois, J. J. and J. Maillard, in Report of the Symposium on Coastal Geodesy, 300-330, Munich, 1970.

Malanotte-Rizzoli, P., B. B. Manca, M. R. d'Alcala, A. Theocharis, S. Brenner, G. Budillon and E. Ozsay, The eastern Mediterranean in the 80s and in the 90s: the big transition in the intermediate and deep circulations, Dyn. Atmos. Oceans, 29, 365-395, 1999.

Roether, W., B. B. Manca, B. Klein, D. Bregant, D. Georgopoulos, V. Beitzel, V. Kovačević and A. Luchetta, Recent Changes in Eastern Mediterranean Deep Waters, Science, 271, 333-335, 1996.

Tsimplis, M. N. and T. F. Baker, Sea level drop in the Mediterranean Sea: An indicator of deep water salinity and temperature changes?, Geophys. Res. Lett., 27, 1731-1734, 2000.

C. Garrett and T. Ross, Department of Physics and Astronomy, University of Victoria, P.O. Box 3055, Victoria, BC V8W 3P6 Canada. (e-mail: garrett@phys.uvic.ca; tetjana@uvic.ca)

P.-Y. Le Traon, Oceanography Department, CLS Space Oceanography Division, 8-10 rue Hermes Parc Technologique du Canal, 31526 Ramonville, Saint-Agne, France. (e-mail: PierreYves.Letraon@cls.fr)

(Received April 5, 2000; accepted July 16, 2000) 